lication date; format, including any particular needs regarding illustrations or typography; arrangement of bibliographical references, i.e., footnotes or endnotes; paper stock; binding; maximum sale price; minimum period during which the volume will remain in print; advertising (number of ads which will coincide with the date of publication); number of review copies to be provided by the publisher; date by which the unit will deliver the final manuscript to the publisher; size of print run; number of offprints for authors and a copy of the book for the editor. The contract must be signed by an ALA department head.

Any volume issued by a commercial publisher must clearly state on its title page and in the preface or introduction that the work was undertaken by an ACRL unit.

\title{
Stress analysis: A case study
}

\author{
By Larry J. Ostler \\ AUL for Personnel and General Services \\ Brigham Young University
}

\author{
and Jin Teik Oon \\ Personnel Assistant \\ Brigham Young University
}

\section{The sources of stress and satisfaction in one academic library.}

$\mathbf{T}$ here's a dirty little secret in the Age of the Office: stress. Our jobs are killing us." Stress on the job affects the morale of workers and bosses in every setting. The library is no exception. Stress, an adaptation to change, is inevitable and constant because the world is constantly changing. How can we cope with stress?

Encouraged by an article in Library Journal entitled "Stress in the Library" we decided to study stress in the Harold B. Lee Library (HBLL) at Brigham Young University. We used the categories already developed by the author Charles Bunge: 1) patrons; 2) workload; 3) supervisors and management; 4) schedule and workday; 5) lack of posi-

\footnotetext{
'Anneta Miller, "Stress on the Job," Newsweek 111 (April 1988): 40.

${ }^{2}$ Charles Bunge, "Stress in the Library," Library Journal 112 (September 1987): 47.
}

tive feedback; 6) other staff members; 7) lack of information and training; 8) feeling pulled and tugged; 9) technology and equipment; 10) physical facilities; 11) bureaucracy and red tape; 12) unchallenging work; 13) failure and uncertainty; 14) change; 15) lack of budget and resources; and 16) miscellaneous.

We divided the Lee Library employees into two groups, faculty and support staff, to test their responses to each of these items. After obtaining the results and feedback from these two sub-groups, we combined and analyzed the overall results. Our goals in this study, in sequential order, were as follows:

1. To understand stress and satisfaction.

2. To identify sources and causes of stress and satisfaction in the organization.

3. To analyze sources and causes of stress and satisfaction. 
4. To recommend methods and measures to deal with stress.

\section{Methodology}

We initiated the study by preparing two questionnaires for collecting data. We organized and conducted an in-house stress workshop for each of the two groups (faculty and support staff) of all three library divisions: General Services, Technical Services, and Collection Development. This workshop discussed general aspects of job stress: what stress is, how it affects people, and how to deal with it. The workshop also addressed positive aspects of working in the library: what employees liked about their job, what made the library their career choice, and what their sources of satisfaction were in all areas of work. All participants completed the two questionnaires after a brief explanation.

Upon completion of the stress workshops, we compiled and calculated the data gathered from the questionnaires. We dealt with each of the two groups and each of the three divisions separately.

After adding up the number of votes for each category of both sources of stress and sources of satisfaction, we assigned weights to each category as follows: 1) sources of stress, rank 1-10, weight $10-1$; 2) sources of satisfaction, rank $1-8$, weight 8-1. We evaluated the percentage for every category, and totaled the average percentage of the combined results of the staff and faculty.

In analyzing and comparing the results, we took the total average percentage of each of the three areas and compared their similarities and differences. The next step was to compare results between the total average percentage of the HBLL and that of Bunge's study. After examining the results, we proposed and recommended the best methods and measures of dealing with stress.

\section{Data analysis and interpretation}

Although we compiled and completed the report with considerable accuracy, several areas of possible improvement exist. Generally, a much more detailed plan, particularly in the area of data compilation and calculation, should have been established prior to the start of the project. Because of the variety of the individual feedback, many responses were inconsistent with the general guidelines established at the start of the project. As a result, we had to modify some aspects of the expectations and be flexible with the anticipation of the general outcome of the report.

The original questionnaires showed several flaws that contributed to the inconsistencies: the audience was not identified, the instructions were unclear and contained several errors, and the examples contained in each category were not sufficiently defined.

Since the questionnaire asked all participants to rank their top ten sources of stress and top eight sources of satisfaction on the job, we discarded sur- veys that were less than half complete and those that did not follow the guidelines (for example: one participant ranked all sources of stress as 1 or 2 ). Some participants used the "others" section to list areas of stress or satisfaction that were already classified under one of the given categories. Therefore, some surveys required us to reassign ranking. If a participant identified more than ten or eight sources, we took the maximum number and dropped the remainder. On the other hand, if a participant did not fully utilize the maximum number of votes, these omissions were added in the "Number of Unused Votes" column. This procedure ensured that the total number of unused votes and the total number of votes identified by the participants for every category would give a sum total that corresponds with the theoretical total number of votes.

After we assigned weights to the respective rank ings, we then totalled up weights for "each" category (A), and "every" category (B). The percentage weight for "each" category is as follows:

$$
\% \text { weight }=(\mathrm{A} / \mathrm{B}) \times 100
$$

The percentage weight for "every" category must sum up to $100 \%$.

This calculation procedure is applicable to both the faculty and support staff groups. A total average percentage weight for "each" category is determined by the equation in Figure 1. Again, the total average percentage weight for "every" category must add up to $100 \%$.

Finally, we obtained the results of the HBLL sources of stress and satisfaction by averaging the total average percentage weight of the three divisions (this is based on the assumption that all three divisions carry equal weight in determining the overall results).

\section{Comparison between the three divisions}

Sources of Stress. Our results indicate a correlation with our initial assumption that the sources of stress would coincide with the area in which the person works. For example, the technical services people have the lowest level of stress with patrons perhaps because of their limited contact with patrons; stress due to routine work is not obvious in the collection development possibly because the nature of the work is generally more varied; the general services people do not experience many changes in policies, project responsibilities, and procedures, possibly explaining why their stress in this category is lowest of all three groups.

Sources of Satisfaction. Several levels of satisfaction stand out: the areas of "Being Around Books" with the Collection Development, "Variety" with Technical Services, and "Positive Feedback" with General Services. Once again, the nature of their work reflects the data collected. 


$$
\text { total average \% weight }=\frac{A_{\text {staff }}+A_{\text {faculty }}}{B_{\text {staff }}+B_{\text {faculty }}} \times 100
$$

Figure 1.

\section{Comparison between HBLL and Bunge's study}

Sources of Stress. The random study by Bunge, when compared with BYU's study shows a higher level of stress when dealing with patrons and supervisor/management. On the other hand, the average results of the random study reveal a much lower stress level in the areas of "Feeling Pulled and Tugged," "Lack of Budget and Resources," "Bureaucracy and Red Tape," and "Technology and Equipment" when compared with that of BYU's.

Sources of Satisfaction. The results of BYU's study disclose four areas of positive feedback: "Problem Solving," "Flexibility and Autonomy," "Learning," and "Being of Service." The lower level of satisfaction in the area of "Patrons" for BYU stands out in comparison with the random study by Bunge.

\section{Discussion and recommendations}

"It's not just the frequency of stress that's increasing; it's the duration." The effects of stress lead to a "decline in productivity, increased absenteeism, and escalating medical costs." We felt that the study of stress and satisfaction in the HBLL should help to evaluate its causes and extent.
As stated by Bunge, "One of the most important general stress-management strategies is the continual development of one's awareness regarding these two aspects of one's self, because controlling and avoiding painful stress is largely a matter of maintaining a balance between the challenges and demands we are under and the resources we have to cope and thrive."

Stress management is the responsibility of both workers and managers. The roles of the supervisors in stress management are many and varied. Supervisors should monitor the sources of stress and satisfaction regularly within their respective departments and then follow up with appropriate actions to try to reduce the areas of stress. A routine "walkaround" to meet, talk, and socialize with employees usually enables frank exchanges of thoughts and ideas. This will enhance the morale of the workers and benefit the management and function of the library.

The workers should also be responsible for controlling and coping with stress. Generally, advice for dealing with stress focuses on relaxation; some advice even suggests fighting back or walking away. The National Institute on Workers Compensation/American Institute of Stress listed the following warning signs and ways to cope with stress.

\section{SOURCES OF STRESS}

Areas

\section{General Services}

Technical Services

Collection Development

Harold B. Lee Library

(total of all divisions)
Highest Category

Workload

Technology/Equipment

Bureaucracy/Red Tape

Workload
Lowest Category

Change

Failure/Uncertainty

Unchallenging Work

Unchallenging Work

\section{SOURCES OF SATISFACTION}

\section{Areas}

\section{General Services}

Technical Services

Collection Development

Harold B. Lee Library

$$
\text { (total of all divisions) }
$$

$$
\text { Highest Category }
$$

Problem Solving

Colleagues

Flexibility/Autonomy

Flexibility/Autonomy
Lowest Category

Students/Children

Students/Children

Being Around Books

Students/Children

Figure 2. 
Warning signs

- Intestinal distress

- Rapid pulse

- Frequent illness

- Insomnia

- Persistent fatigue

- Irritability

- Nail-biting

- Lack of concentration

- Increased use of alcohol or drugs

- Hunger for sweets

\section{Ways to cope}

-Maintain a sense of humor

- Meditate

- Get a massage

- Exercise regularly

- Eat more sensibly

- Limit intake of alcohol and caffeine

-Take refuge in family and friends

- Delegate responsibility

- Stand up to the boss

-Quit

\section{Summary}

Stress is not inherited, rather the work environment - or how people interpret their work environment - is a major contributor of stress. Improving most stress situations requires time, money, and sincere effort; however, the elimination or manipulation of stress can be accomplished.

Although the study could have been improved by establishing a better plan prior to the start of the project, it provided us with valuable data. The results in Figure 2 (see previous page) show the highest and lowest categories of stress and satisfaction from the general comparison of the three divisions.

When compared with our results, the study by Bunge showed a higher level of stress when dealing with patrons and supervisor/management. The lower level of satisfaction in the area of "patrons" in the HBLL also stood out in comparison with the study by Bunge. This correlates with Bunge's observation that many or most aspects of library jobs are not inherently stressful; rather, whether or not they produce stress depends on the situation or other factors.

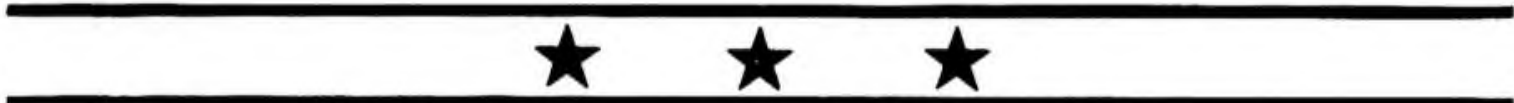 Avulg fram the ffipld}

\section{Acquisitions}

- The Auburn University Archives, Alabama, recently acquired the photographs and measured drawings of the Alabama collection of the Historic American Building Survey (HABS). Nicholas H. Holmes III, Mobile architect, was instrumental in obtaining the HABS for Auburn University. The Historic American Building Survey originated in 1933 under federal relief programs and became permanent in 1934 through an agreement between the Library of Congress and the American Institute of Architects. Included in the collection are hundreds of black and white photographs taken between 1930 and 1960 representing structures in 27 Alabama counties. Some of the structures represented in the holdings have since been demolished, making this collection an important documentation of the outstanding historic buildings of Alabama.

- Boston University has received a gift of papers representing over a quarter of a century of Congressional banking history from Fernand St. Germain of Rhode Island, former chairman of the House of Representatives Banking Committee.
The collection contains a large store of materials from St. Germain's 28 years in Congress including legislative histories of bills he sponsored as chair of the House Committee on Banking Affairs (1980-1988) and as chair of the House Subcommittee on Financial Institutions (from 1972) and 28 years of congressional correspondence, constituent mail, and casework. It contains a wealth of information related to the history and development of government regulation and oversight of financial institutions.

- California State Polytechnic University's W.K. Kellogg Arabian Horse Library, Pomona, has acquired the research library of noted Arabian horse authority Gladys Brown Edwards. The approximately 2,500 -volume collection was presented by an anonymous donor after the death of Edwards. The material includes many rare editions, such as an 1881 printing of Gleanings from the Desert of Arabia. Receipt of the gift was made possible by the donation of $\$ 1,100$ for relocation expenses by Mrs. Joseph Paul of Claremont, California.

-Indiana State University, Terre Haute, has re- 